\title{
Passive absorber design for mechanical vibrations with base excitation
}

\author{
Diseño de amortiguadores pasivos para vibraciones mecánicas con excitación en la \\ base
}

VÁZQUEZ-GONZÁLEZ, Benjamín†๋*, JIMÉNEZ-RABIELA, Homero, RAMÍREZ-CRUZ, José Luis and QUINTANA-DÍAZ, María Berenice Guadalupe

Universidad Autónoma Metropolitana, Unidad Azcapotzalco, División de Ciencias Básicas e Ingeniería, Departamento de Energía

ID $1^{\text {st }}$ Author: Benjamín, Vázquez-González / ORC ID: 0000-0002-9030-5662, Researcher ID Thomson: S-2417-2018, CVU CONACYT ID: 25749

ID $1^{\text {st }}$ Co-author: Homero, Jiménez-Rabiela/ ORC ID: 0000-0002-1549-0853, Researcher ID Thomson: S-2299-2018, CVU CONACYT ID: 123386

ID $2^{\text {nd }}$ Co-author: José Luis, Ramírez-Cruz / ORC ID: 0000-0003-0762-2630, Researcher ID Thomson: G-3405-2019, CVU CONACYT ID: 921268

ID $3^{\text {rd }}$ Co-author: María Berenice Guadalupe, Quintana-Díaz / ORC ID: 0000-0002-4703-1934, CVU CONACYT ID: 1015523

DOI: $10.35429 /$ JOIE.2021.16.5.8.15

Recibido 19 de Marzo, 2021; Aceptado 30 de Junio, 2021

\section{Abstract}

The dynamic coupling of mechanical vibratory systems results in the oscillatory interaction between the bodies of the system as a whole, for a certain selection of some parameters the phenomenon of vibration absorption occurs, in this phenomenon the main system transfers its mechanical energy to the absorber, resulting in a minimum amplitude of movement of the primary system and the absorber develops a certain amplitude. In this work it is proposed to design a vibration absorber for a primary system that in turn is affected by the motion in the base, which produces vibrations, the motion in the base includes elastic and viscous actions. It has been possible to determine a set of parameters that allow the absorption of vibrations, likewise, the parameters determined not only allow the absorption, but also establish a transfer of the effect of the damping present in the base to the absorber.

Passive control, Damping transference, Vibrations absorber

\begin{abstract}
Resumen
El acoplamiento dinámico de sistemas vibratorios mecánicos tiene como resultado la interacción oscilatoria entre los cuerpos del sistema en conjunto, para una selección determinada de algunos parámetros se produce el fenómeno de la absorción de vibraciones, en este fenómeno el sistema principal, transfiere su energía mecánica al absorbedor, dando como resultado que la amplitud del movimiento del sistema primario sea mínima y el absorbedor desarrolla una amplitud determinada. En este trabajo se plantea diseñar un absorbedor de vibraciones para un sistema primario que a su vez es afectado por el movimiento en la base, lo cual produce vibraciones, el movimiento en la base incluye acciones elásticas y de tipo viscoso. Se ha logrado determinar un conjunto de parámetros que permiten la absorción de vibraciones, así mismo los parámetros determinados no sólo permiten la absorción, sino que establecen una transferencia del efecto del amortiguamiento presente en la base hacia el absorbedor.
\end{abstract}

Control pasivo, Transferencia de amortiguamiento, Absorbedor de vibraciones

Citation: VÁZQUEZ-GONZÁLEZ, Benjamín, JIMÉNEZ-RABIELA, Homero, RAMíREZ-CRUZ, José Luis and QUINTANA-DÍAZ, María Berenice Guadalupe. Passive absorber design for mechanical vibrations with base excitation. Journal of Innovative Engineering. 2021. 5-16: 8-15

\footnotetext{
*Correspondence to Author (e-mail: bvg@azc.uam.mx)
}

$\dagger$ Researcher contributing as first Author. 


\section{Introduction}

The first studies related to the interaction between bodies that develop a vibratory motion are reported in Frham's patent, in this work the existence of a relationship between the frequencies of vibration motion is established, there being a coupling in the movement that induces a reduction or attenuation between a main system and another auxiliary. Initially Den Hartog establishes a dynamic vibration absorber, like that device represented by two bodies coupled by means of elastic elements, in this device it is not considered viscous damping and in its study the relationship of parameters is determined to ideally cancel the amplitude of motion of the primary mass or main system.

Starting from the undamped vibration absorber, damping is included with the intention of extend the attenuation or absorption bandwidth, for which new techniques are developed, that result in obtaining optimal parameters. Ozer and Royston continued with the search for optimal parameters in the undamped case, Puzyrov and Awrejcewicz recognize the importance and validity of the passive absorber problem and propose techniques for the optimal selection of absorber parameters. The problem of optimal parameter selection is also of practical importance, as Swayze and Rivin consider.

In the dynamic vibration absorber problem, there are two possible cases, the most common corresponds to the situation in which the main system is subjected to the direct action of a disturbing force of known amplitude and frequency, the second case corresponds to the situation in which the force that disturbs the primary system comes from its base, that is, there is a transmission problem with damping.

In this work the problem of determining the optimal parameters in the sense of ideally to reduce the amplitude of the primary system is studied, for the case of transmissibility by means of an absorber without viscous damping. In the developed analysis, we determined that, if the value of the elastic constant of the primary system is choose, then the motion amplitude of the absorber will be regulated, as well as the primary system transient response.

\section{Vibration absorber with excitation in the base}

This section presents a description of the mechanical system, as well as the statement of the problem, to later obtain a model of the dynamic system.

Figure 1 shows the primary system of mass $m_{1}$ coupled to its absorber of mass $m_{2}$, the coupling between the primary and secondary systems it is established exclusively by the elastic device $k_{2}$. The primary system is in an environment that induces a harmonic type of motion or vibrations.

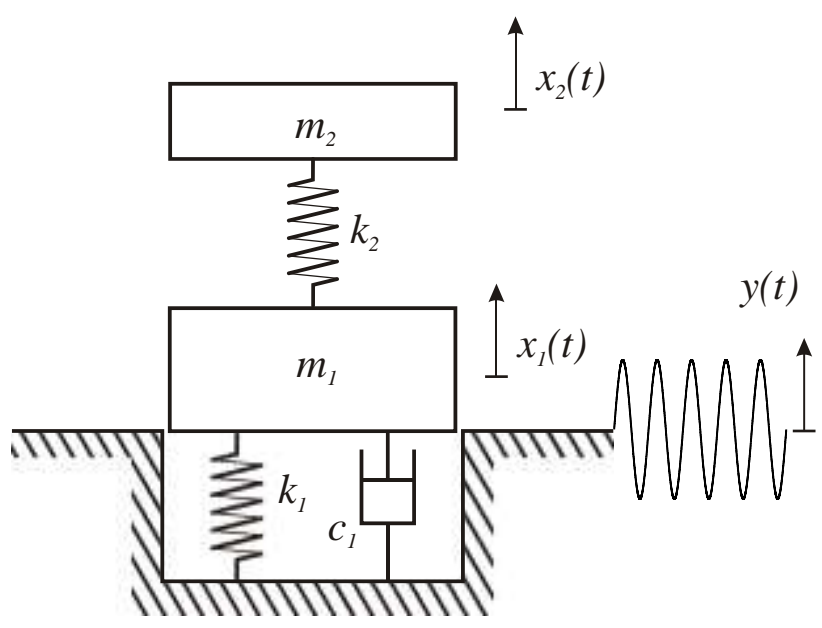

Figure 1 Vibration absorber $m_{2}$ for the primary system $m_{1}$

The base is the support or environment on which the mass of the primary system is it allocated, this support is it represented together as the elastic and viscous dynamic behavior that the system perceives. The mathematical model is obtained by evaluating the actions that directly affect each mass of the system, for the primary system we have,

$\sum F_{1}=m_{1} \ddot{x}_{1}$

$\sum F_{1}=-k_{1}\left(x_{1}-y\right)-c_{1}\left(\dot{x}_{1}-\dot{y}\right)-k_{2}\left(x_{1}-\right.$

$\left.x_{2}\right)-c_{2}\left(\dot{x}_{1}-\dot{x}_{2}\right)$

The equations for the secondary system are,

$\sum F_{2}=m_{2} \ddot{x}_{2}$

$\sum F_{2}=-k_{2}\left(x_{2}-x_{1}\right)-c_{2}\left(\dot{x}_{2}-\dot{x}_{1}\right)$

By developing and simplifying the above equations, it turns out 
$m_{1} \ddot{x}_{1}+k_{1} x_{1}+c_{1} \dot{x}_{1}-k_{2} x_{1}-k_{2} x_{2}+c_{2} \dot{x}_{1}-$

$c_{2} \dot{x}_{2}=k_{1} y+c_{1} \dot{y}$

$m_{2} \ddot{x}_{2}+k_{2} x_{2}-k_{2} x_{1}+c_{2} \dot{x}_{2}-c_{2} \dot{x}_{1}=0$

In equation (6) the dynamic condition of minimum motion has been established, and in its case null motion, for this reason it is equal to what we can call dynamical not motion o zero motion. Considering that the base develops a harmonic motion $y=Y \sin (\omega t)$, equation (5) finally is,

$m_{1} \ddot{x}_{1}+k_{1} x_{1}+c_{1} \dot{x}_{1}-k_{2} x_{1}-k_{2} x_{2}+c_{2} \dot{x}_{1}-$

$c_{2} \dot{x}_{2}=k_{1} Y \sin (\omega t)+c_{1} \omega Y \cos (\omega t)$

Because the mechanical system is dynamically coupled, the effects of the primary system are transmitted to the secondary system, inheriting the latter the characteristics of the primary system, which in turn develops a harmonic type movement, for this reason, to solve the equations (6) and (7), the following harmonic solutions are proposed,

$$
\begin{aligned}
& x_{1}(t)=X_{11} \operatorname{sen}(\omega t)+X_{12} \cos (\omega t) \\
& x_{2}(t)=X_{21} \operatorname{sen}(\omega t)+X_{22} \cos (\omega t)
\end{aligned}
$$

By substituting equations (8) and (9), in equations (6) and (7), the algebraic system of equations results on,

$$
\begin{aligned}
& -\omega^{2} m_{1} X_{11}-\omega^{2} m_{1} X_{12}+k_{1} X_{11}- \\
& \omega c_{1} X_{12}+k_{2} X_{11}-k_{2} X_{21}-k_{1} Y=0 \\
& k_{1} X_{12}+\omega c_{1} X_{11}+k_{2} X_{12}-k_{2} X_{22}-k_{1} \omega Y=0 \\
& -\omega^{2} m_{2} X_{22}+k_{2} X_{21}-k_{2} X_{11}=0 \\
& k_{2} X_{22}-k_{2} X_{12}-\omega^{2} m_{2} X_{21}=0
\end{aligned}
$$

The system equations (10)-(13), can be written in matrix form as follows,

$$
\begin{gathered}
{\left[\begin{array}{cccc}
k_{1}+k_{2}-\omega^{2} m_{1} & -\omega^{2} m_{1}-\omega c_{1} & -k_{2} & 0 \\
-\omega c_{1} & k_{1}+k_{2} & 0 & -k_{2} \\
-k_{2} & 0 & k_{2} & -\omega^{2} m_{2} \\
0 & -k_{2} & -\omega^{2} m_{2} & k_{2}
\end{array}\right]} \\
{\left[\begin{array}{l}
X_{11} \\
X_{12} \\
X_{21} \\
X_{22}
\end{array}\right]=\left[\begin{array}{c}
k_{1} Y \\
\omega c_{1} Y \\
0 \\
0
\end{array}\right]}
\end{gathered}
$$
as follows,

The system equations solutions (14) are

$$
\begin{aligned}
& X_{11}=\left(c_{1} m_{1} m_{2}^{2} \omega^{7}+\omega^{6} c_{1}^{2} m_{2}^{2}+\left(k_{1} k_{2} m_{2}^{2}+\right.\right. \\
& \left.k_{1}^{2} m_{2}^{2}\right) \omega^{4}-\left(c_{1} k_{2}^{2} m_{1}+c_{1} k_{2}^{2} m_{2}\right) \omega^{3}- \\
& \left.c_{1}^{2} k_{2}^{2} \omega^{2}-k_{1}^{2} k_{2}^{2}\right) Y / \Delta \\
& X_{12}=\left(-c_{1} m_{1} m_{2}^{2} \omega^{7}+c_{1} k_{2} m_{2}^{2} \omega^{5}+\right. \\
& \left.k_{1} k_{2} m_{2}^{2} \omega^{2}+c_{1} k_{2}^{2} m_{1} \omega^{3}\right) Y / \Delta \\
& X_{21}=\left(c_{1} k_{2} m_{1} m_{2} \omega^{5}-\left(c_{1} k_{2}^{2} m_{2}+\right.\right. \\
& \left.\left.c_{1} k_{2}^{2} m_{1}\right) \omega^{3}--c_{1}^{2} k_{2}^{2} \omega^{2}-k_{1}^{2} k_{2}^{2}\right) Y / \Delta \\
& X_{22}=\left(-c_{1} k_{2} m_{1} m_{2} \omega^{5}-c_{1}^{2} k_{2} m_{2} \omega^{4}+c_{1} k_{2}^{2} m_{1} \omega^{3}-\right. \\
& \left.\left(k_{1} k_{2}^{2} m_{2}+k_{2} k_{1}^{2} m_{2}\right) \omega^{2}\right) Y / \Delta
\end{aligned}
$$

where the denominator is the determinant of the system,

$$
\begin{aligned}
& \Delta=c_{1} m_{1} m_{2}^{2} \omega^{7}+\left(c_{1}^{2} m_{2}^{2}-k_{1} m_{1} m_{2}^{2}-\right. \\
& \left.k_{2} m_{1} m_{2}^{2}\right) \omega^{6}+\left(2 k_{1} k_{2} m_{2}^{2}+m_{1} m_{2} k_{2}^{2}+\right. \\
& \left.k_{1}^{2} m_{2}^{2}+k_{2}^{2} m_{2}^{2}\right) \omega^{4}-\omega^{3} c_{1} m_{1} k_{2}^{2}+\left(k_{1} m_{1} k_{2}^{2}-\right. \\
& \left.c_{1}^{2} k_{2}^{2}\right) \omega^{2}-k_{1}^{2} k_{2}^{2}
\end{aligned}
$$

\section{Solution methodology}

The problem of the absorber dynamic vibration seeks to find the values of the parameters which reduce the amplitude of the main system motion to the minimum, which analytically expressed as a zero amplitude, which leads to set the following conditions, $X_{11}=X_{12}=0$. To achieve the above, the following is analytically posed as,

$$
\begin{aligned}
& c_{1} m_{1} m_{2}^{2} \omega^{7}+c_{1}^{2} m_{2}^{2} \omega^{6}+\left(k_{1} k_{2} m_{2}^{2}+\right. \\
& \left.k_{1}^{2} m_{2}^{2}\right) \omega^{4}-\left(c_{1} k_{2}^{2} m_{1}+c_{1} k_{2}^{2} m_{2}\right) \omega^{3}- \\
& c_{1}^{2} k_{2}^{2} \omega^{2}-k_{1}^{2} k_{2}^{2}=0 \\
& -c_{1} m_{1} m_{2}^{2} \omega^{7}+c_{1} k_{2} m_{2}^{2} \omega^{5}+c_{1} k_{2}^{2} m_{1} \omega^{3}+ \\
& k_{1} k_{2} m_{2}^{2} \omega^{2}=0
\end{aligned}
$$

in this way, the system equations solution, (20)-(21), will allow to determine the minimum amplitude parameters of the primary system. The solution strategy consists of proposing values that allow the equality be satisfied with maximum absorption condition, in the undamped case this occurs for the relationship (see Den Hartog),

$k_{2}=\omega^{2} m_{2}$ 
When evaluating the proposed solution (22) in the systems equations (20) and (21), in both cases the condition reached is,

$k_{1}=\omega c_{1}$

We call equation (23), as a damping tuning condition.

Since the two equations (20) and (21) converge to the same condition, we concluded that equality (23) is the solution sought.

This way of expressing the solution, coincides with the one proposed in the principle of the vibration absorber, which consists of proposing values that satisfy the equalities of zero amplitude.

Therefore, the value of the elastic stiffness is modified and chosen to obtain a vibration absorber with damping, and therefore with a stable state, which is not present in the case of the undamped absorber.

\section{Simulation results}

This section shows the simulation results for the absorber with the elastic constant in the primary system according with the equation (23). Evaluation of the absorber performance is realized by comparing it with the case on which damping tuning condition is not accomplished. The elastic constant of the primary system could be quantified by dynamic tests, such as, exciting the system with a frequency that produces resonance, in this way, knowing the mass of the system, the numerical value of elastic constant is determined.

The set of equations of the problem solution is extensive considering the viscous damping presence at the base of the primary system, the system of equations is now extended to a system of $4 \times 4$ equations, about the undamped case, this results in very long algebraic expressions with exponents up to the seventh power in the excitation frequency. The numerical simulation allows to get a result directly for variations of the significant parameters, in this case, the significant parameters are the elastic constant $k_{l}$ and the viscous damping $c_{1}$.
The solutions evaluation of the extensive algebraic expressions with high powers is carried out by means of a set of numerical simulations, to verify the effective absorption behavior. The effect on the response of both subsystems when modifying a single parameter is not evident, however, equation (23) presents a guideline to propose and evaluate the result of choose the parameters that an absorber can present, likewise, with the result obtained in the present work, it has been determined that it is possible to modify the parameters of the base, to obtain the desired performance of the primary system and influence on the performance of the absorber.

\section{Numerical experiments}

We have performed numerical experiments to compare the effects of considering the damping by the result of equation (23). The proposed numerical values are arbitrary taken, but their selection makes it possible to show clear the differences that occur when equations (22) and (23) are took into account as design conditions.

The order of the simulations is as follows, first is show the result of not considering the condition established by the damping tuning, then a simulation is show considering said condition, in each case first the performance over time of the primary system is show, denoted by $x_{l}$ and later the secondary one, denoted by $x_{2}$.

Table 1 shows the parameters corresponding to Figures 2 and 3. Figure 2 shows the time response of the primary system for a damping value of $c_{1}=10 \mathrm{~N} \cdot \mathrm{s} / \mathrm{m}$, and an arbitrary value of the elastic constant $k_{l}=400$ $\mathrm{N} / \mathrm{m}$, we observe that the amplitude of the primary system $x_{1}$, reduces its amplitude due to the absorber, which fulfills its function by the tuning condition (equation (22)), we note the presence of a transient state response at approximately $13 \mathrm{sec}$.

\begin{tabular}{|c|c|l|c|}
\hline $\mathrm{m}_{1}=4 \mathrm{~kg}$ & $\mathrm{c}_{1}=10 \mathrm{Ns} / \mathrm{m}$ & $\mathrm{k}_{1}=400 \mathrm{~N} / \mathrm{m}$ & $\mathrm{Y}=0.05 \mathrm{~m}$ \\
\hline $\mathrm{m}_{2}=0.5 \mathrm{~kg}$ & & $\mathrm{k}_{2}=50 \mathrm{~N} / \mathrm{m}$ & $\omega=10 \mathrm{rad} / \mathrm{s}$ \\
\hline
\end{tabular}

Table 1 First parameters experiment

In Figure 3, the absorber performance denoted by $x_{2}$, it registers a permanent steady state amplitude of about $0.4 \mathrm{~m}$ of, as well as the presence of a small lapse of transitory state. 


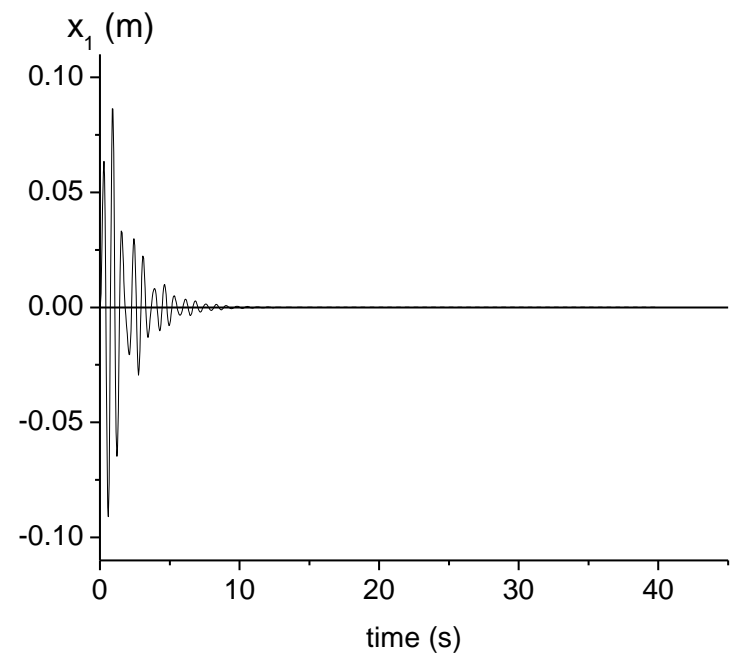

Figure 2 Time response of the primary system for arbitrary values $\mathrm{k}_{1}=400 \mathrm{~N} / \mathrm{m}, \mathrm{c}_{1}=10 \mathrm{~N} \cdot \mathrm{s} / \mathrm{m}$

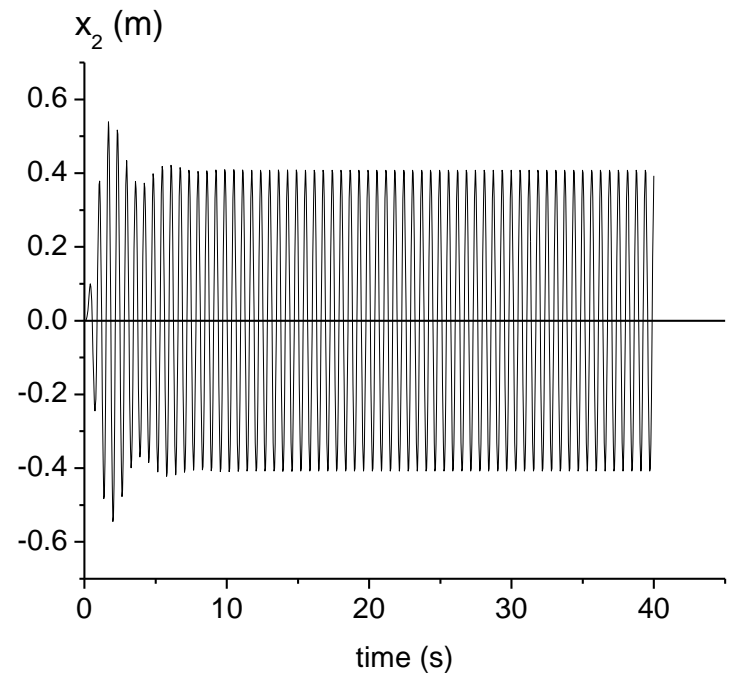

Figure 3 Time response of the secondary system for arbitrary values $\mathrm{k}_{1}=400 \mathrm{~N} / \mathrm{m}, \mathrm{c}_{1}=10 \mathrm{~N} \cdot \mathrm{s} / \mathrm{m}$

Table 2 shows the numerical values of the parameters for the tuning conditions that correspond to Figures 4 and 5.

\begin{tabular}{|c|l|l|c|}
\hline $\mathrm{m}_{1}=4 \mathrm{~kg}$ & $\mathrm{c}_{1}=10 \mathrm{Ns} / \mathrm{m}$ & $\mathrm{k}_{1}=100 \mathrm{~N} / \mathrm{m}$ & $\mathrm{Y}=0.05 \mathrm{~m}$ \\
\hline $\mathrm{m}_{2}=0.5 \mathrm{~kg}$ & & $\mathrm{k}_{2}=50 \mathrm{~N} / \mathrm{m}$ & $\omega=10 \mathrm{rad} / \mathrm{s}$ \\
\hline
\end{tabular}

Table 2 Second parameters experiment

In Figure 4, we observe attenuation of the amplitude for the primary system $x_{1}$ to a minimum value, it is also observed that there is a longer transient state time, in relation to the response of Figure 2, in the present case the condition for tuning by damping is fulfill. However, in Figure 5, which corresponds to the performance over time of the secondary system, we observe a decrease in the amplitude $x_{2}$ in the steady state.
It occurs on a small range of time, this corresponding to the transitory state, comparing with Figure 3, where the condition of tuning by damping is not present.

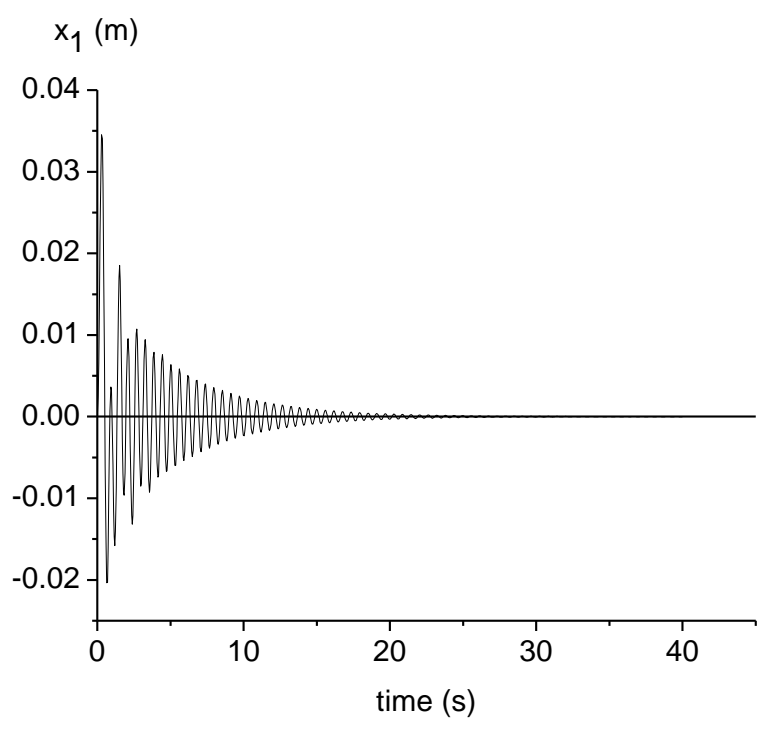

Figure 4 Time response of the primary system for the tuning values $\mathrm{k}_{1}=100 \mathrm{~N} / \mathrm{m}, \mathrm{c}_{1}=10 \mathrm{~N} \cdot \mathrm{s} / \mathrm{m}$

Note in Figure 5, that the decrease in the amplitude of the secondary system is significant in relation to Figure 3, of the same subsystem but under tuned conditions, note also that vibration absorption isn't lost.

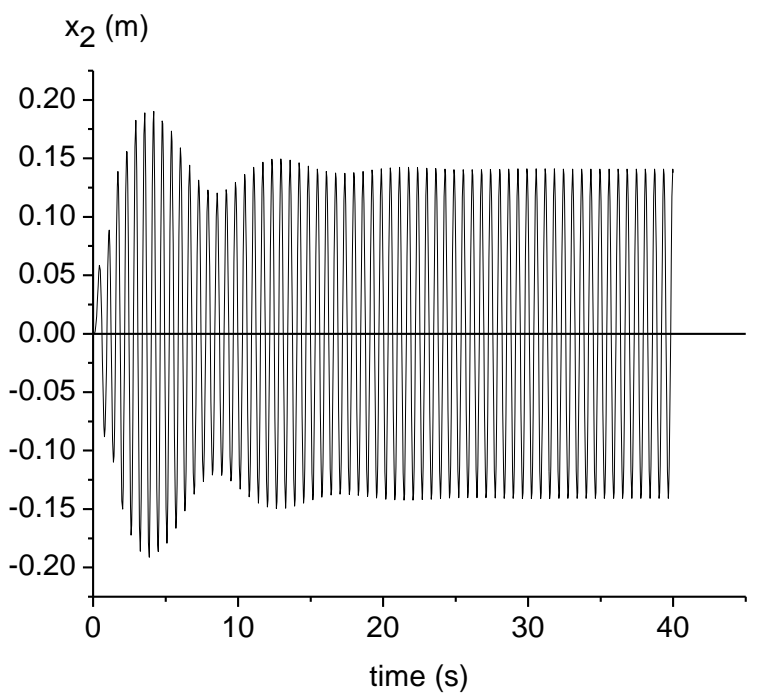

Figure 5 Time response of the secondary system for the tuning values, $\mathrm{k}_{1}=100 \mathrm{~N} / \mathrm{m}, \mathrm{c}_{1}=10 \mathrm{~N} \cdot \mathrm{s} / \mathrm{m}$

In Table 3, the numerical values of the parameters corresponding to Figures 6 and 7 are shown. In this case, the value of the viscous damping $c_{l}$ has been modified to evaluate its effect on the absorption and on the reduction of the amplitude of the system secondary, the proposed value is higher than in the two previous experiments, the value of the elastic constant $k_{l}$ has also been modified.

VÁZQUEZ-GONZÁLEZ, Benjamín, JIMÉNEZ-RABIELA, Homero, RAMÍREZ-CRUZ, José Luis and QUINTANA-DÍAZ, María Berenice Guadalupe. Passive absorber design for mechanical vibrations with base excitation. Journal of Innovative Engineering. 2021 


\begin{tabular}{|l|l|l|l|}
\hline $\mathrm{m}_{1}=4 \mathrm{~kg}$ & $\mathrm{c}_{1}=15 \mathrm{Ns} / \mathrm{m}$ & $\mathrm{k}_{1}=600 \mathrm{~N} / \mathrm{m}$ & $\mathrm{Y}=0.05 \mathrm{~m}$ \\
\hline $\mathrm{m}_{2}=0.5 \mathrm{~kg}$ & & $\mathrm{k}_{2}=50 \mathrm{~N} / \mathrm{m}$ & $\omega=10 \mathrm{rad} / \mathrm{s}$ \\
\hline
\end{tabular}

Table 3 Third parameters experiment

In Figure 6, the performance over time of the primary system is it shown, in this case is not considered the tuning condition by damping, the amplitude $x_{1}$ of the transient state is slightly bigger than in the case of Figure 4, where the damping is lower, also we observe that by increasing damping, there is a slight effect on the reduction on the transient time in the primary system.

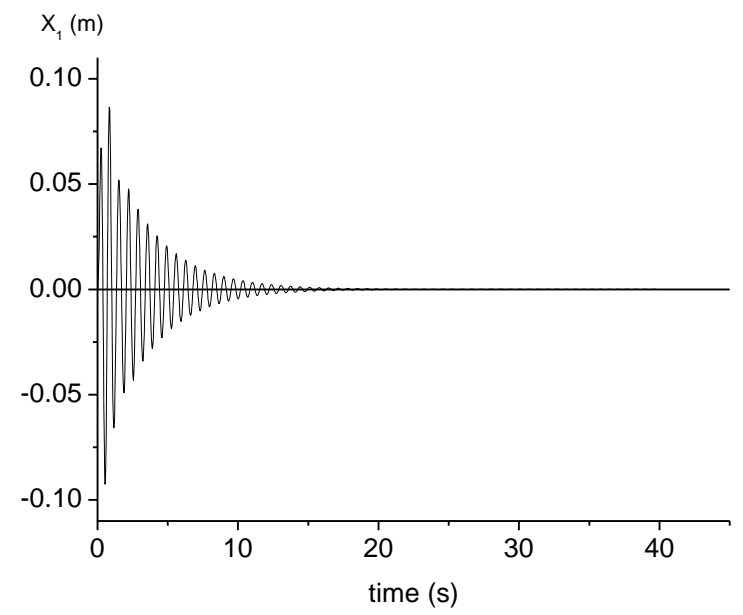

Figure 6 Time response of the primary system for values without tuning by damping, $\mathrm{k}_{1}=600 \mathrm{~N} / \mathrm{m}, \mathrm{c}_{1}=15 \mathrm{~N} \cdot \mathrm{s} / \mathrm{m}$

It is also observed that the fundamental effect of absorption is maintained, we remember that the tuning condition for elastic effect (equation (22)) is it fulfilled in each experiment, which ensures absorption.

In Figure 7, the time response data of the secondary system are in Table 3 , including the conditions for no tuning by damping. It is observed that the amplitude is greater than in the case of Figure 5, in which the damping is less, a slight transient is also observed.

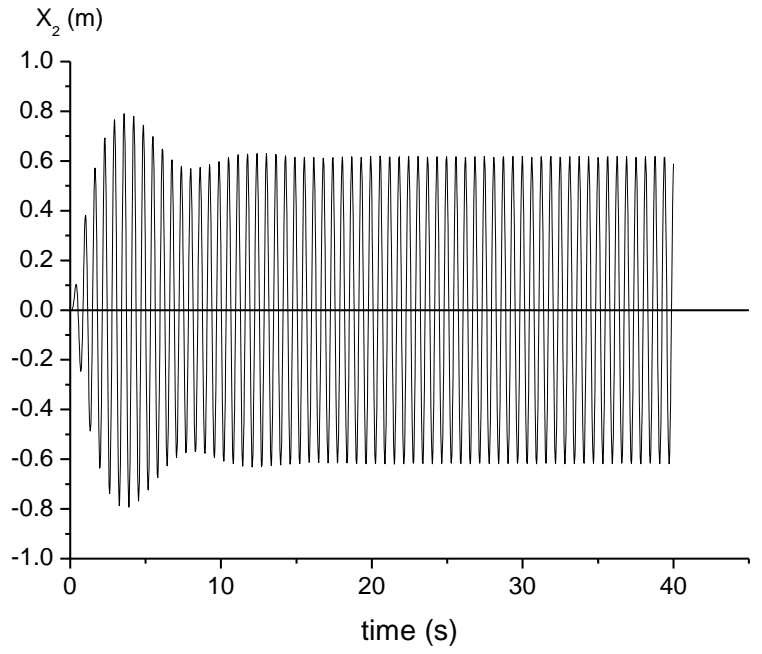

Figure 7 Time response of the secondary system for values without tuning by damping, $\mathrm{k}_{1}=600 \mathrm{~N} / \mathrm{m}, \mathrm{c}_{1}=15$ $\mathrm{N} \cdot \mathrm{s} / \mathrm{m}$

In Table 4, which corresponds to the last set of numerical experiments, the numerical values that meet the damping tuning condition are considered, but maintaining the same viscous damping value as the previous case, to compare with the results of the third experiment..

\begin{tabular}{|c|c|l|c|}
\hline $\mathrm{m}_{1}=4 \mathrm{~kg}$ & $\mathrm{c}_{1}=15 \mathrm{Ns} / \mathrm{m}$ & $\mathrm{k}_{1}=150 \mathrm{~N} / \mathrm{m}$ & $\mathrm{Y}=0.05 \mathrm{~m}$ \\
\hline $\mathrm{m}_{2}=0.5 \mathrm{~kg}$ & & $\mathrm{k}_{2}=50 \mathrm{~N} / \mathrm{m}$ & $\omega=10 \mathrm{rad} / \mathrm{s}$ \\
\hline
\end{tabular}

Table 4 Fourth parameters experiment

Figure 8 shows the time response for the primary system $x_{1}$, in this case, again amplitude response decrease is it observed in the period corresponding to the transient time, in relation to the previous one (Figure 6), is it obtained better absorption.

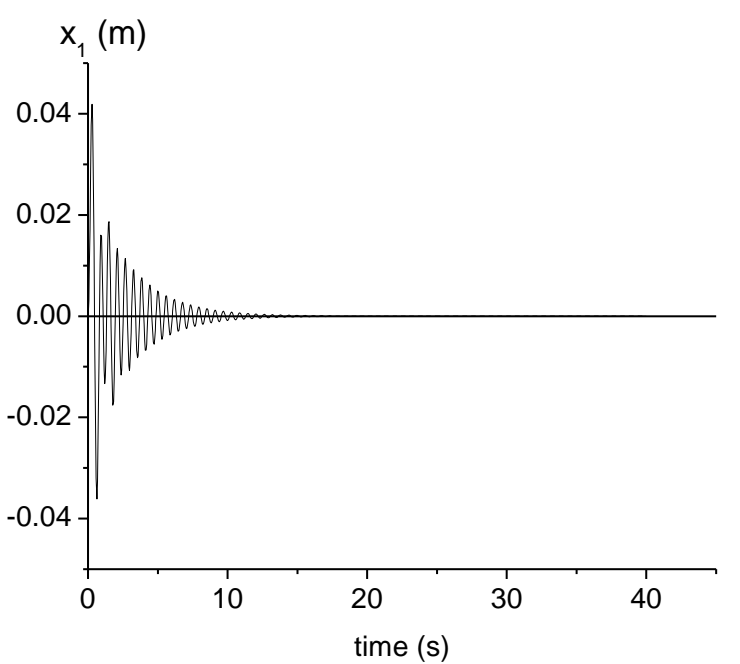

Figure 8 Time response primary system for values with damping tuning, $\mathrm{k}_{1}=150 \mathrm{~N} / \mathrm{m}, \mathrm{c}_{1}=15 \mathrm{~N} \cdot \mathrm{s} / \mathrm{m}$ 
Figure 9 shows the time response for the absorber in comparison with the previous one experiment, using tuning by damping condition, is it observed that the amplitude $x_{2}$ decreases related to the case not tuned by damping. (Figure 7), likewise, is it observed a small reduction in the transient.

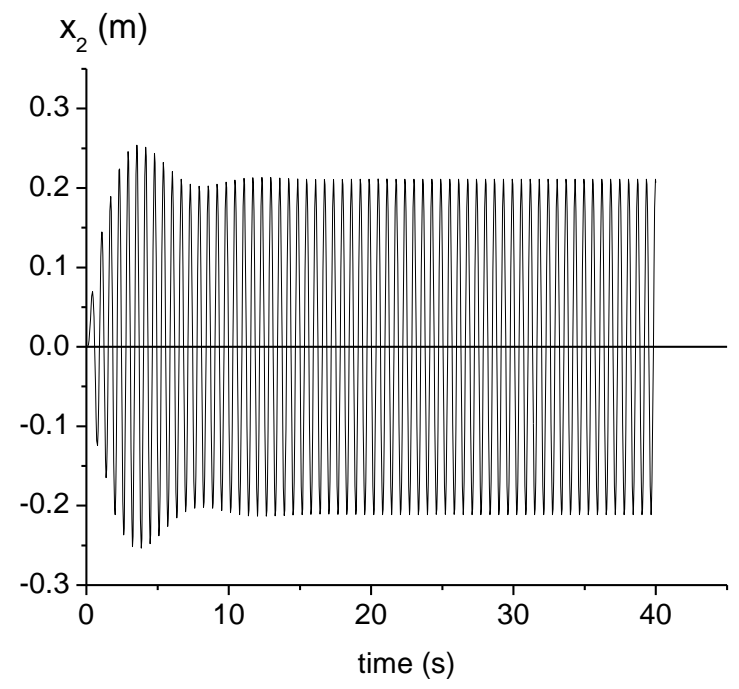

Figure 9 Time response of the secondary system for values with damping tuning, $\mathrm{k}_{1}=150 \mathrm{~N} / \mathrm{m}, \mathrm{c}_{1}=15 \mathrm{~N} \cdot \mathrm{s} / \mathrm{m}$

\section{Discussion results}

In the experimentally developed cases, the vibration absorption of the primary system is it obtained, this performance is due to the tuning by elastic rigidity condition, as established by Den Hartog, this always allows the tuning between two oscillating bodies producing the absorption. When considering the tuning by damping condition, a slight increase on the transient time response of the primary system occurs, as well as a reduction in the amplitude of the secondary system, along with vibrations absorption.

The effect of damping is known as the cause on the increase of the time transitory state, from the numerical simulations the transfer of damping to the secondary or absorber system is it observed, as well as the decrease in the amplitude response in the time of the transient. It is clear that the only physical element or mechanical coupling device is the spring, so the fundamental result of this work is to have observed that the elastic element also transmits the effect of viscous damping through the body of the elastic element, that is.
The elastic element includes an action composed of, the elastic effect and the viscous damping effect for a single element or physical device. When evaluating equation (17) to (19), the amplitude of the absorber only depends on $c_{1}, Y, m_{2}$ and $\omega$, in the conditions of tuning by damping and elasticity,

$$
X_{2}=\frac{-2 c_{1} Y}{\omega m_{2}}=\frac{-2 \omega c_{1} Y}{\omega^{2} m_{2}}=\frac{-2 \omega c_{1} Y}{k_{2}}
$$

which shows that the spring $k_{2}$ transmits the damping effect.

\section{Acknowledgement}

The authors are grateful for the institutional support to the Universidad Autónoma Metropolitana and the Azcapotzalco Campus, in particular the División de Ciencias Básicas e Ingeniería, also to the Departamento de Energía.

\section{Conclusions}

In this work equations to diminish the perturbation of a mechanical system were developed, the vibrations at the base of the main system, includes inherent damping and elasticity, the motion on the base produces transmissibility of the forces, that comes from the base and are towards the system of main interest. The vibration absorber does not include viscous type damping, it only includes a mass and an elastic coupling, the absorber reduces the vibrations when is it tuned by means of the elastic coupling, absorbing the vibrations with the main system, in such a way that the phenomenon of absorption occurs, however, it has been found that under certain conditions of tuning of the damping, the effect of this tuning in the damping is transferred too to the absorber, producing a transitory state in both masses and reducing the amplitude response of the absorber.

\section{References}

Den Hartog J P. Mechanical vibrations. Dover Publications Inc; 1985.

H. Frahm, "Device for damping vibrations of bodies", US989958A, United States Patent 989, 958. Patented Apr. 18, 1911.1911.

Ozer, M. B., and Royston, T. J., "Extending Den Hartog's Vibration Absorber Technique to Multi-Degree-of-Freedom Systems", ASME. J. Vib. Acoust. August 2005; 127(4): 341-350.

VÁZQUEZ-GONZÁLEZ, Benjamín, JIMÉNEZ-RABIELA, Homero, RAMÍREZ-CRUZ, José Luis and QUINTANA-DÍAZ, María Berenice Guadalupe. Passive absorber design for mechanical vibrations with base excitation. Journal of Innovative Engineering. 2021 
Puzyrov V, Awrejcewicz J. "On the optimum absorber parameters: revising the classical results". Journal of Theoretical and Applied Mechanics. 2017; 55(3):1081-1089.

Swayze, J. and Rivin, E., "Improvements in the Optimization of Dynamic Vibration Absorbers," SAE Technical Paper 971934, 1997. 